\title{
A INFLUÊNCIA DA EXPANSÃO URBANA EM APP: ÊNFASE AO PERÍMETRO URBANO DE SANTA GERTRUDES - SP
}

\author{
Helton Henrique Alvarinho ${ }^{(a)}$; Andréia Medinilha Pancher ${ }^{(b)}$ \\ (a) Departamento de Planejamento Territorial e Geoprocessamento/Universidade Estadual Paulista / \\ helton.alvarinho@gmail.com \\ (b) Departamento de Planejamento Territorial e Geoprocessamento/Universidade Estadual Paulista / \\ medinilh@rc.unesp.br
}

Eixo: Uso e ocupação das terras e legislação ambiental

\begin{abstract}
Resumo
O presente estudo teve por objetivo analisar a expansão urbana, e os reflexos nas Áreas de Proteção Permanente (APP) no perímetro urbano do município de Santa Gertrudes-SP (cenários de 1995 e 2010), através do uso de geotecnologias. Assim, foi realizado o mapeamento de uso do solo urbano dos dois cenários por meio de fotointerpretação, e por vetorização manual das feições de interesse no SIG ArcGIS. Também, efetuou-se a análise de distância (buffer), com base na legislação vigente (Lei $\mathrm{n}^{\mathrm{o}}$ 12.651/2012), relativa às Áreas de Proteção Permanente (APP). Para os dois cenários, foram produzidas as faixas de proteção, as quais foram sobrepostas aos mapas de uso do solo urbano, resultando nos Mapas de Conflito de Uso. Com base nos resultados, constatou-se que apesar do aumento da vegetação em algumas áreas, principalmente as matas ciliares, não houve uma recuperação da maior parte das áreas analisadas, as quais em grande maioria estão completamente desprotegidas.
\end{abstract}

Palavras-chave: Urbanização; Análise evolutiva; Impactos ambientais; Áreas de Proteção Permanente.

\section{Introdução}

O intenso impulso na urbanização brasileira ocorreu na segunda metade do século XX, pois até 1950 ainda predominava uma população rural e um modelo agrário-exportador. Contudo, nessa metade de século o país viveu a importante transição para o modelo urbano-industrial, que já era realidade em países mais desenvolvidos.

Entre 1940 e 1980, dá-se verdadeira inversão quanto ao lugar da residência da população brasileira. Há meio século (1940), a taxa de urbanização era de 26,35\%, em 1980 alcança $68,86 \%$. Nesses quarenta anos, triplica a população total do Brasil, ao passo que a população urbana se multiplica por sete vezes e meia. (SANTOS, 2009, p. 31).

A industrialização foi a grande catalisadora da transformação do país rural e agrícola para um país urbano e metropolitano, que provocou o movimento da mão de obra do campo para as cidades, gerando uma rápida concentração de grande contingente de pessoas nos núcleos urbanos. 
Nesse contexto, nas primeiras décadas do século XX iniciou-se pelos imigrantes europeus a indústria cerâmica no município de Santa Gertrudes, localizado no interior do estado de São Paulo. Esse processo colocou o município em evidência quanto ao potencial econômico vindo da exploração das argilas da Formação Corumbataí e promoveu um verdadeiro salto no crescimento urbano de Santa Gertrudes. De acordo com Garcia (2003), na década de 1980 a atividade era tão dominante na cidade que $80 \%$ dos trabalhadores eram ceramistas, e mais de $80 \%$ da população já vivia cidade (GARCIA, 2003).

Assim, para avaliar a influência do crescimento da cidade nas Áreas de Proteção Permanente (APP), devese adotar uma escala temporal, a fim de analisar as mudanças ocorridas ao longo do tempo. Para Carlos (2001, p.51) a dimensão temporal para os estudos urbanos é extremamente importante: “[...] é essencialmente algo não definido, pois não pode ser analisada como um fenômeno pronto e acabado, pois as formas que a cidade assume ganham dinamismo ao longo do processo histórico. A cidade tem uma história”.

$\mathrm{Na}$ análise dessa temática, a geografia, sendo uma ciência que tem seu foco central na relação espaço sociedade presta uma contribuição extraordinária junto à história no estudo urbano. Segundo Abreu (1998)

"O resgate da memória de um lugar, da memória de uma determinada cidade, só é possível se pudermos trabalhar ao mesmo tempo em duas frentes de investigação. Temos que aliar a base segura da análise histórica ao esteio não menos seguro que a geografia proporciona" (ABREU, 1998, p. 18).

Diante do exposto, o principal objetivo desse trabalho foi analisar a expansão urbana do município de Santa Gertrudes-SP, e os reflexos desse crescimento nas Áreas de Proteção Permanente (APP) de córregos, nascentes e represamentos nos cenários de 1995 e 2010, com base no uso das geotecnologias.

\section{Breves Considerações sobre Santa Gertrudes SP}

O município de Santa Gertrudes está localizado entre as coordenadas geográficas $47^{\circ} 28^{\prime}$ e $47^{\circ} 35^{\prime} \mathrm{O}$ e $22^{\circ} 25^{\prime}$ e $22^{\circ} 32^{\prime}$ S, no interior do Estado de São Paulo e faz divisa com os municípios de Rio Claro (a norte e a oeste); Iracemápolis (ao sul); Araras (a nordeste) e Cordeirópolis (a sudeste). Faz parte da Região Administrativa de Campinas e da Mesorregião de Piracicaba, na porção centro-leste do Estado de São Paulo. A área territorial é de $98,3 \mathrm{~km}^{2}$, abrigando 25.192 habitantes (estimativa do IBGE, 2016), portanto, a densidade demográfica é de aproximadamente 256,3hab./ $\mathrm{km}^{2}$.

Santa Gertrudes faz parte de uma das regiões mais desenvolvidas do interior do estado de São Paulo. Na economia local se sobressai a produção de revestimentos cerâmicos, onde a cidade é o cerne do maior polo cerâmico da América Latina, abrangendo 85\% da produção do Estado de São Paulo, que corresponde 
a $70 \%$ da produção nacional (ASPACER, 2016). O Índice de Desenvolvimento Humano Municipal é de 0,737 (IDHM 2010), portanto, compreende a classe com IDHM alto (entre 0,700 a 0,799). Localiza-se a 167 quilômetros da capital São Paulo e possuí acesso através de entroncamento com a rodovia estadual Washington Luís, uma das rodovias mais importantes do Estado de São Paulo.

Cabe ressaltar, que para a realização deste trabalho, foi considerado somente o perímetro urbano de Santa Gertrudes (figura 1).

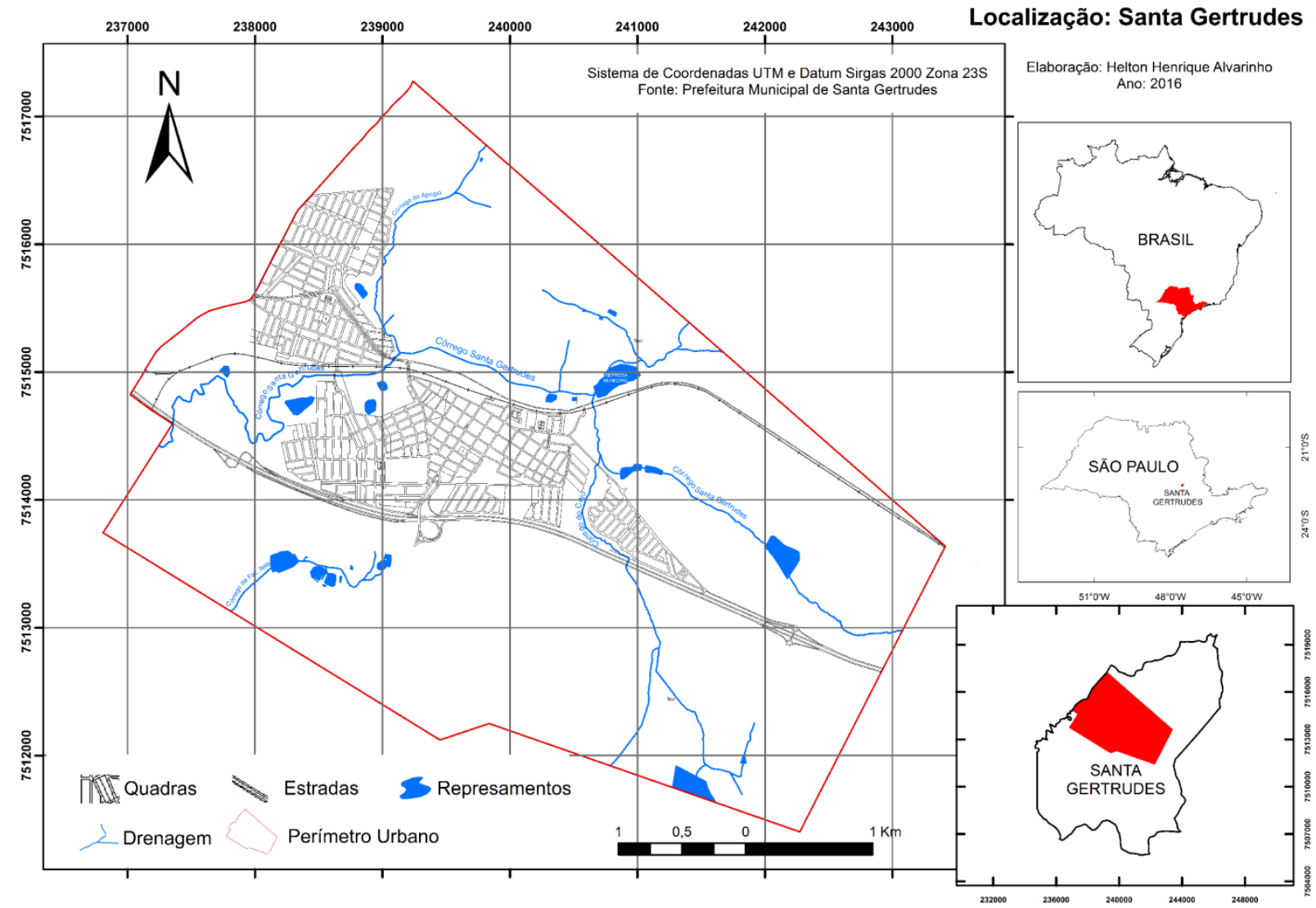

Figura 1 - Localização da área de estudo. Fonte: Alvarinho, 2016.

Durante as quatro primeiras décadas do século XX, Santa Gertrudes deixou de ser um pequeno povoamento para se tornar um Distrito do Município de Rio Claro, em 1918; já era, portanto, uma pequena vila. Décadas depois, em 24 de Dezembro de 1948, desmembrada de Rio Claro, é então elevada à categoria de Município (GARCIA, 2003). Apesar de Santa Gertrudes já haver desenvolvido atividades econômicas diversificadas ainda quando era um distrito de Rio Claro, nessa fase também se iniciava a atividade econômica mais famosa do município, a indústria cerâmica, que produzia telhas graças à grande oferta de matéria prima da região (GARCIA, 2003). 
A existência de matéria prima (argila) em abundância e de qualidade foi determinante para o intenso desenvolvimento da indústria cerâmica em Santa Gertrudes; por isso, é importante destacar alguns aspectos descritivos das formações geológicas existentes nesse território. $\mathrm{O}$ município abrange predominantemente o afloramento de duas unidades litológicas: a formação Corumbataí, integrante do Grupo Passa Dois, e a formação Serra Geral, do Grupo São Bento. De idade neoperniana a eotriássica, segundo Landim (1967) a formação Corumbataí é composta por duas sequências: uma inferior, composta por siltitos cinza escuro a preto, folhelhos cinza escuros a roxo que apresentam estruturas maciças e compostas por fraturas do tipo conchoidal; e uma superior, caracterizada pela intercalação de leitos carbonáticos, argilitos, siltitos e areias finas. Essa formação é a principal fonte de matéria prima para a atividade cerâmica na região, e abarca todo o perímetro urbano de Santa Gertrudes.

Em meados da década de 1980, a indústria cerâmica deu um grande salto, com o sistema de monoqueima em substituição à produção artesanal; em 1993, com a instalação de um moderno laboratório de análises, ampliou-se ainda mais a competitividade para os pisos e revestimentos produzidos em Santa Gertrudes. Esse processo atraiu uma grande quantidade de trabalhadores do campo e de outros estados do Brasil, que se instalaram no local, juntamente com suas famílias (GARCIA, 2003). Atualmente Santa Gertrudes é o principal município do Polo Cerâmico de Santa Gertrudes, que também abrange os municípios de Araras, Charqueada, Cordeirópolis, Ipeúna, Iracemápolis, Limeira, Piracicaba e Rio Claro. Esse complexo cerâmico é o maior polo da América Latina, produzindo 85\% da produção do Estado de São Paulo, que corresponde a 70\% da produção nacional (ASPACER, 2016).

Segundo dados da Prefeitura Municipal, em 2012 existiam 19 cerâmicas na cidade, sendo todas localizadas no perímetro urbano. Entre 1991 e 2000, período no qual o estado São Paulo estabelecia o crescimento da rede urbana nos eixos de desenvolvimento do interior, Santa Gertrudes, assim como muitas cidades médias e pequenas da região, registrou um aumento, em torno de 51\%, passando de 10.485 para 15.898 habitantes em 2000. Entre 2000 e 2010 essa taxa caiu um pouco, para 36\%, e o município ultrapassou os 20 mil habitantes, chegando a 21.634, sendo 18.607 pessoas na área urbana e 189 na zona rural (IBGE, 2010).

\section{Procedimentos Metodológicos}

\subsection{Levantamento de dados e análise bibliográfica}

A etapa do levantamento dados e da análise bibliográfica tive como objetivo o conhecimento das características da área de estudo e a fundamentação teórico-metodológica para o desenvolvimento deste 
trabalho. Assim, foram selecionadas referências sobre a dinâmica urbana, visando entender o processo de expansão urbana em Santa Gertrudes nos cenários de 1995 e de 2010. Foi também consultada a legislação ambiental no que se refere às Áreas de Proteção Permanente (APP) para análise da efetividade do cumprimento das determinações dessa lei (Lei no 12.651/2012) nos cenários estudados.

\subsection{Procedimentos para o Mapeamento do Uso do Solo Urbano de Santa Gertrudes SP}

As fotografias aéreas analógicas de Santa Gertrudes passaram por processos de transformação, a fim de prepará-las para à fotointerpretação e mapeamento manual, bem como para a classificação supervisionada. Já as Ortofotos, como foram fornecidas georreferenciadas, serviram de base para o georreferenciamento das imagens aerofotogramétricas. Assim, seguem as etapas:

\section{a) Conversão das imagens de Analógica para Digital}

As imagens aerofotogramétricas de 1995, na escala de 1:25.000, foram originalmente produzidas pela empresa Base Arerofotogrametria como arquivos analógicos. Deste modo, foi necessário convertê-las em arquivos digitais, através do processo de digitalização de imagem, num scanner de alta resolução (A0). Assim, foram salvas na extensão .tif, para serem inseridas no ambiente do SIG ARCGIS.

\section{b) Georreferenciamento}

O georreferenciamento consiste na operação de transformação geométrica, visando compatibilizar dados espaciais que se referem à mesma região geográfica. Com isto, os conjuntos de dados registrados ficam referenciados ao mesmo sistema de coordenadas. Para o georreferenciamento das imagens aerofotogramétricas, adotou-se o sistema de coordenadas UTM e o Datum SIRGAS 2000, Zona 23S, utilizando-se o software ArcGis.

Vale salientar, que adotou-se a função polinomial, onde os parâmetros são determinados a partir das coordenadas de pontos homólogos. Estes correspondem a feições da base de dados que também podem ser identificados no sistema de referência, chamados de pontos de controle (RICHARDS, 1993).

Através da ferramenta Georreferencing do ArcGIS, os pontos de controle foram identificados visualmente e inseridos na imagem não georreferenciada; posteriormente identificado e inserido no ponto homólogo da imagem de referência (Ortofoto). Para ambas imagens, foram selecionados 8 e 7 pontos de controle, respectivamente. Esses foram regularmente distribuídos, garantindo-se a qualidade do posicionamento de toda a área, atingindo-se o Padrão de Exatidão Cartográfica (PEC) Classe A (tabela I). O PEC é 
determinado pelo Decreto $\mathrm{n}^{\circ} 89.817$ de 20/06/1984, cujo artigo 8 normatiza Instruções Reguladoras de Normas Técnicas da Cartografia Nacional.

Tabela I - Erros nas imagens aerofotogramétricas de 1995

\begin{tabular}{ccc}
\hline Pontos de Controle & Erros - Imagem 1 & Erros - Imagem 2 \\
\hline 1 & 5,11998 & 2,839458 \\
2 & 2,13569 & 3,76376 \\
3 & 3,08586 & 4,7217 \\
4 & 4,26975 & 1,49118 \\
5 & 0,315597 & 1,01235 \\
6 & 0,564746 & 6,43286 \\
7 & 4,16315 & 1,89382 \\
8 & 3,76044 & --- \\
\hline Total RMS Error & $\mathbf{3 , 3 6 1 9 2}$ & $\mathbf{3 , 6 3 9 8 1}$ \\
\hline
\end{tabular}

Elaboração: Alvarinho; Pancher, 2016.

As imagens aerofotogramétricas georreferenciadas formaram um mosaico representativo da área urbana de Santa Gertrudes. Com base neste mosaico, utilizando-se comandos de desenho do SIG/ARCGIS, foram elaborados os mapeamentos temáticos da área urbana.

\section{c) Mapeamentos temáticos do Uso do Solo Urbano de Santa Gertrudes SP: cenários de 1995} e 2010

Os mapeamentos de uso e ocupação das terras do município de Cordeirópolis e do uso do solo urbano do perímetro urbano de Santa Gertrudes, foram realizados considerando-se dois cenários, um de 1995, anterior ao intenso desenvolvimento do polo cerâmico; e, outro de 2010, de considerável desenvolvimento da indústria cerâmica e de intenso crescimento urbano.

Em razão da alta resolução espacial das imagens aerofotogramétricas e das Ortofotos digitais, e do elevado nível de detalhe necessário para a análise proposta nessa pesquisa, optou-se pela fotointerpretação e pelo mapeamento manual das feições presentes nas imagens, utilizando-se os recursos de desenho e edição do software ArcGIS versão 10.1 .

Cabe ressaltar, que os dados vetoriais relativos à drenagem, limite do perímetro urbano, estradas, ferrovia, quadras, foram obtidos a partir da planta cadastral digital (em.$d w g$ ) do município de Santa Gertrudes (2012), fornecida pela Prefeitura Municipal. A planta cadastral também foi georreferrenciada no sistema de coordenadas UTM Datum Sirgas 2000 Zona 23. Utilizando-se os recursos de edição do ArcGIS foi possível corrigir erros existentes na planta original, selecionando-se layers importantes para essa pesquisa, destacando-se o perímetro urbano de Santa Gertrudes, que serviu de recorte geográfico para os mapeamentos temáticos. 
De acordo com o Manual de Uso da Terra do IBGE (2015), o uso da terra pode ser interpretado como um conjunto de fatos ou fenômenos espaciais, e é de fundamental importância para a compreensão da dinâmica dos processos políticos, econômicos e sociais de uma área ou região, de modo a conhecer as tipologias de usos, a fim de poder definir os padrões de usos.

Diante do exposto e para contemplar o nível de detalhe e refinamento necessários para a distinção das feições, somente após a análise interpretativa das imagens, do levantamento de bibliografia e levantamento de campo é que foram definidas 11 classes de uso do solo urbano de Santa Gertrudes SP. Para cada classe temática foram criados arquivos vetoriais (shapefiles), contendo dados específicos de sua classe temática de uso do solo; também, foram atribuídas cores distintas, a fim de discriminar as classes temáticas.

Os mapeamentos de uso e ocupação do solo urbano dos cenários de 1995 e 2010 permitiram analisar o avanço do processo de urbanização dentro do perímetro urbano do município de Santa Gertrudes. Com os recursos de desenho do ArcGIS foram desenhados manualmente os polígonos correspondentes a cada classe temática, organizando-os em camadas (layers) diferentes, tomando cuidado para não haver a sobreposição de polígonos de classes temáticas distintas, que poderiam mascarar os dados.

Após o mapeamento, com o uso das ferramentas Calculate Geometry e Field Calculator foi possível calcular a área $\left(\mathrm{m}^{2}\right)$ ocupada por cada classe temática, assim como a porcentagem de área ocupada por cada uma delas no perímetro urbano. Para complementar o mapa temático, foram adicionados os arquivos vetoriais das quadras, estradas e drenagem, aspectos importantes associados às classes de uso.

\section{Resultados e Discussões}

O mapa de uso do solo urbano de 1995 abrangeu 11 classes temáticas, predominando a classe cultura (50,6\%), seguindo-se pela classe campo $(21,0 \%)$ e residencial $(7,1 \%)$. A mancha urbana possui um formato alongado, no sentido leste - oeste, ocupando a área entre a ferrovia e a rodovia Washington Luiz. Nesse período, verifica-se que a expansão urbana já estava se intensificando, devido aos loteamentos que se observa nas porções noroeste e sudoeste da mancha urbana. (figura 2). 

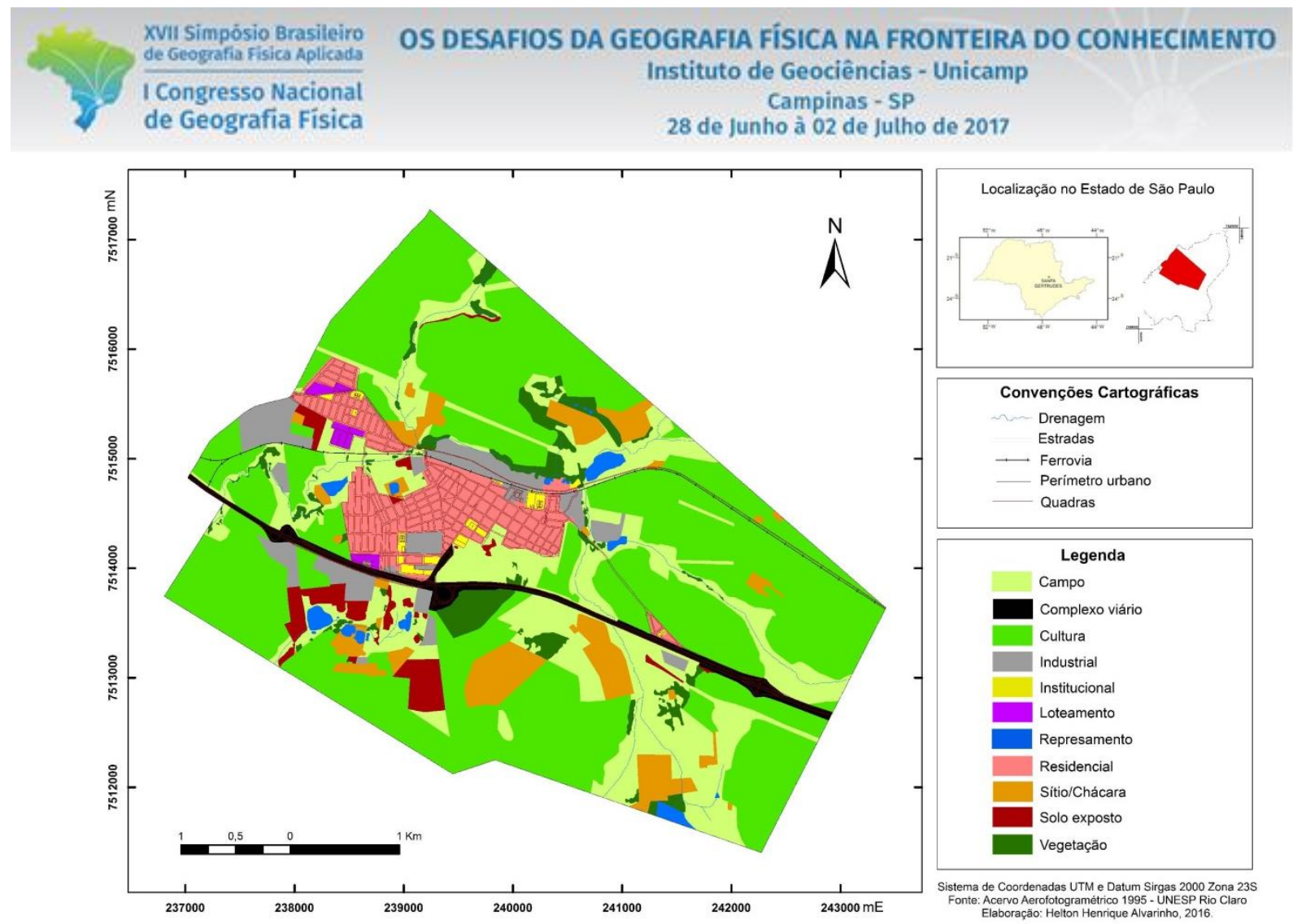

Figura 2 - Uso do Solo Urbano - Santa Gertrudes SP - 1995

O mapa da figura 3 demonstra a faixa buffer no entorno da drenagem existente no perímetro urbano de Santa Gertrudes e o conflito de uso do solo urbano em 1995 na APP. O principal uso em APP é o de campo $(68,8 \%)$, seguindo-se pelas classes vegetação $(19,1 \%)$ e industrial $(18,8 \%)$, respectivamente. Os outros usos ocupam pequenas manchas da área onde legalmente deveria haver a vegetação ciliar. Assim, verifica-se que os usos urbanos exercem forte pressão sobre os recursos hídricos, causando a redução da vegetação, o que pode provocar processos erosivos, assoreamento dos canais d'água, enchentes, poluição hídrica. 


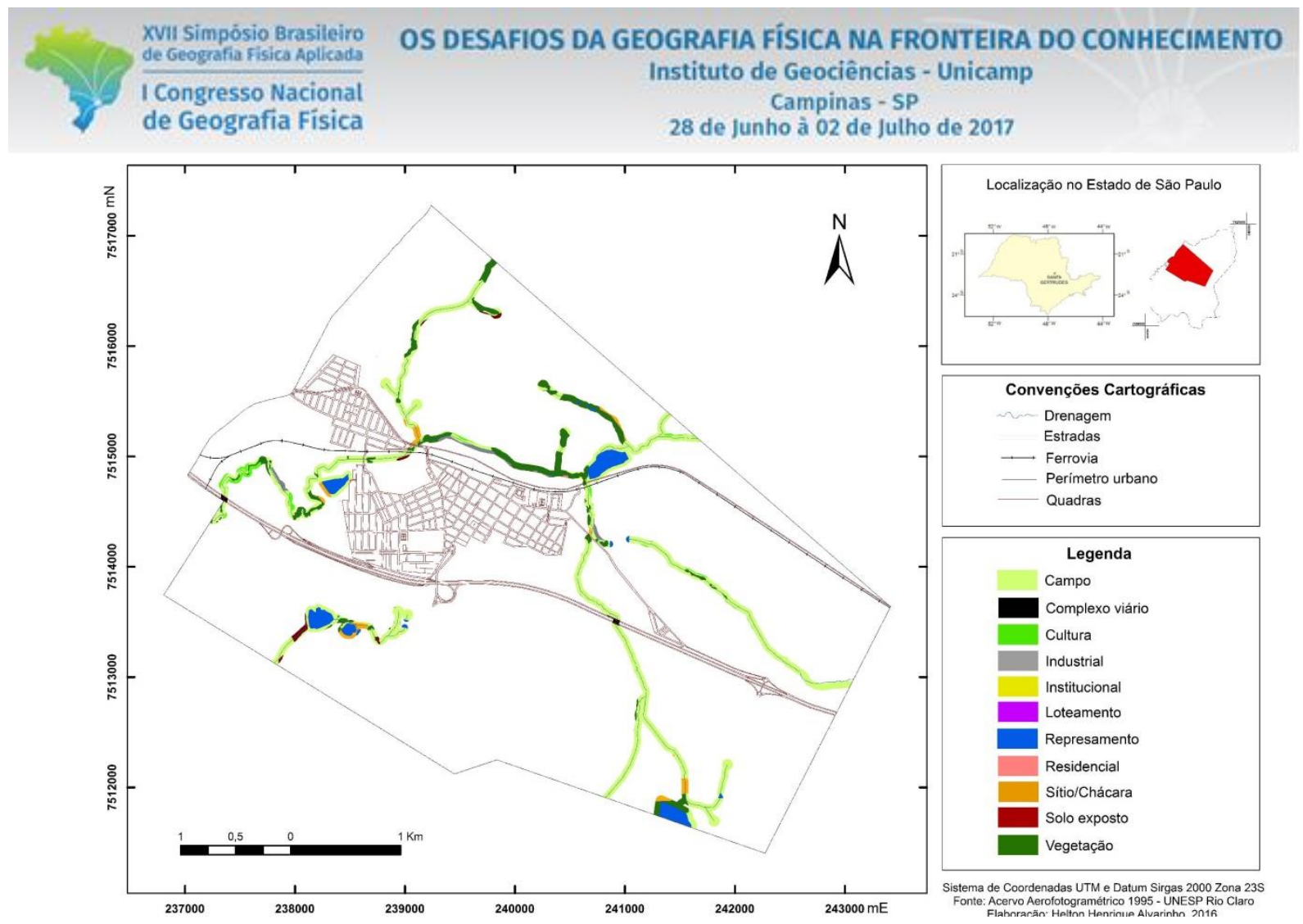

Figura 3 - Conflito de Uso do Solo Urbano - Santa Gertrudes SP - 1995. Fonte: Alvarinho, 2016.

No cenário de 2010, observam-se alterações nos usos do solo urbano, destacando-se o aumento da classe residencial (de 7,1\% para 12\%), principalmente na direção noroeste; houve também expansão na direção sul da mancha urbana. Aspecto que merece ressalva é que a vegetação embora não atendia a legislação (Lei $\mathrm{n}^{\circ} 12.651 / 12$ ) aumentou no período analisado, de $4 \%$ para $6,6 \%$. A classe campo reduziu (de $21 \%$ para 20,4\%), sendo ocupada pelas classes cultura, industrial e residencial. A classe industrial teve um aumento expressivo, de 4,6\% para 11,6\%. A cultura também se ampliou consideravelmente (de 2,8\% para $35,9 \%$ ). (figura 4 ). 


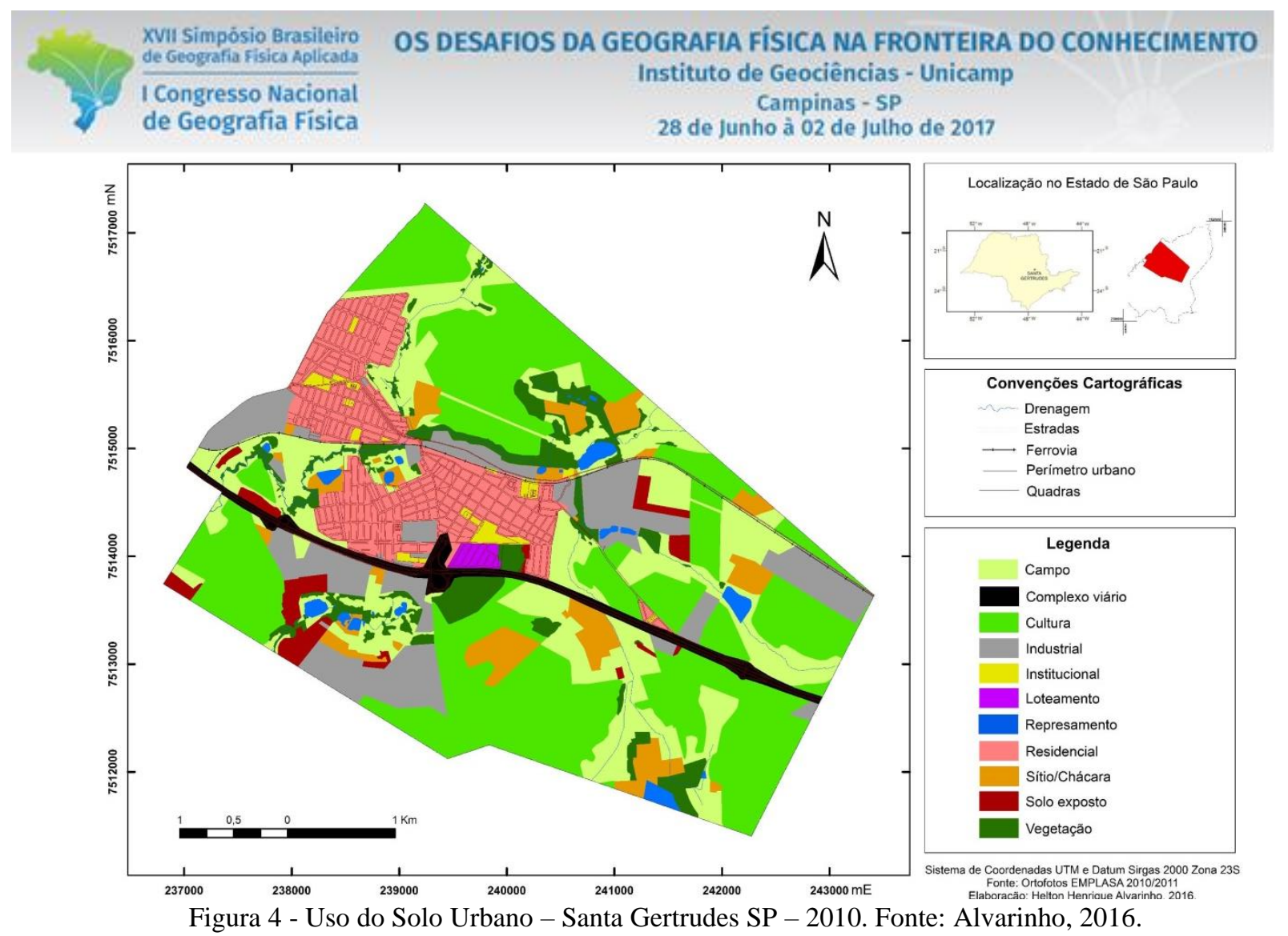

Analisando-se a figura 5, relativa ao conflito de uso do solo urbano em APP, em 2010, observa-se que houve um aumento do uso residencial (de $0,2 \%$ para $0,8 \%$ ), uma redução da área da classe solo exposto (de $1,7 \%$ para $0,4 \%$ ). Vale salientar, que de modo positivo, houve uma ampliação da classe vegetação, de 19,1\%, em 1995, para 33,9\%, em 2010. Outras classes que tiveram alterações no período analisado foram: campo (de $69,8 \%$ para $54,9 \%$ ), cultura (de $2,8 \%$ para $0,6 \%$ ), sítio/chácara (de 3,8\% para 5,3\%). 


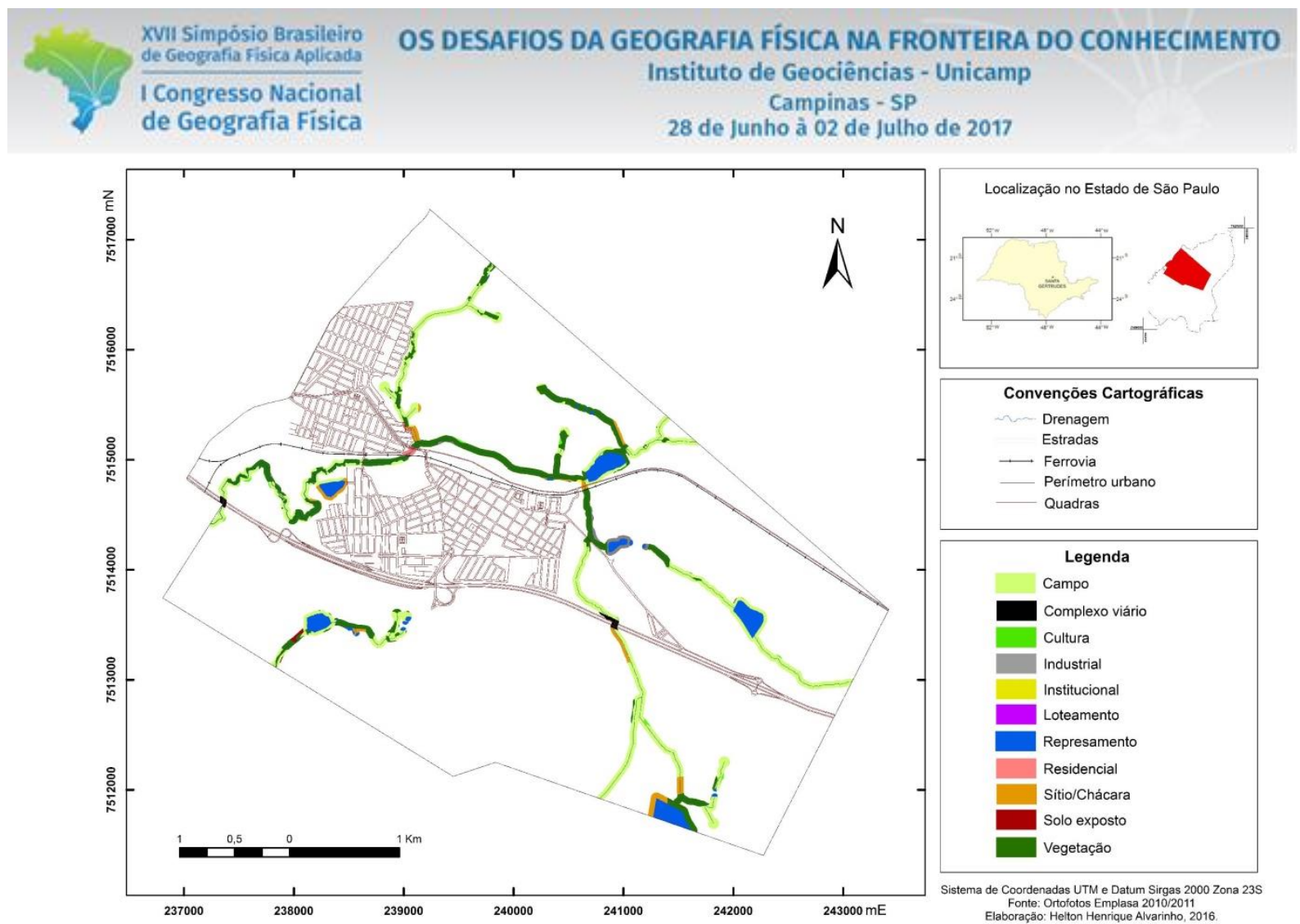

Figura 5 - Conflito de Uso do Solo Urbano - Santa Gertrudes SP - 2010. Fonte: Alvarinho, 2016.

Desse modo, apesar de ter havido uma redução, a classe campo ainda é o uso predominante na área de APP, onde deveria existir somente vegetação ciliar.

\section{Considerações Finais}

O desenvolvimento da indústria cerâmica em Santa Gertrudes gerou a concentração das atividades produtivas na área urbana, e alterou completamente a dinâmica territorial do que era apenas um pequeno aglomerado urbano nas margens da estrada de ferro. Esse processo potencializou a migração, o desenvolvimento econômico e a expansão da malha urbana da cidade, mas impôs consequências e demandas socioambientais diversas.

Assim, considerando-se a importância da análise da expansão da cidade e dos impactos ambientais desse processo, mais especificamente referente à aplicação da legislação mais atual no que se refere às Áreas de Proteção Permanente (APP) em cursos d'água, represamentos e nascentes, a metodologia desenvolvida nesse trabalho se mostrou satisfatória. $\mathrm{O}$ uso das geotecnologias foi fundamental, considerando-se que essas ferramentas permitem ao planejador avaliar de modo consistente áreas com características complexas, integrando-se dados das mais diversas fontes, e processando-os de forma rápida com um custo muito reduzido. 
Ao espacializar a ocupação do solo urbano em dois cenários (1995 e 2010), e quantificar as alterações nas classes de uso do solo urbano, foi possível destacar que tanto a malha urbana da cidade, quanto à área industrial estão em franca expansão dentro do perímetro urbano. Entre os cenários de 1995 e 2010, foi possível notar que a expansão do tecido urbano se deu basicamente nos eixos Noroeste, sentido município de Rio Claro, numa região periférica, que fica separada da parte central pela passagem do córrego Santa Gertrudes; Oeste, conectada ao centro, limitado ao córrego Santa Gertrudes nesse sentido, e paralelo à rodovia Washington Luís; Sul, as margens da rodovia Washington Luís. Em 2010 a região Noroeste já estava conurbada com o município de Rio Claro.

Em ambos os períodos analisados, as indústrias foram se desenvolvendo no entorno imediato da malha urbana, e nas margens da rodovia Washington Luís, formando distritos industriais nas porções sul e nordeste. A análise evolutiva permitiu realizar um diagnóstico sobre a realidade de Santa Gertrudes, revelando um processo de intensa atividade cerâmica, que estimulou o crescimento urbano acelerado e refletiu em vários problemas, destacando-se o desmatamento das APP. Na grande maioria, as áreas de APP dos córregos, represamentos e nascentes estão completamente depredadas, sem cobertura vegetal, e em grande parte cercada por gramíneas e vegetação arbustiva esparsa.

\section{Bibliografia}

ABREU, M. A. Sobre a Memória das Cidades. In: Revista Território - LAGET/UFRJ, n 4, Ano III, Jan/Jun. 1996. Disponível em <http://www.revistaterritorio.com.br/pdf/04_2_abreu.pdf.> Acesso em: 10 de setembro, 2016.

ALVARINHO, H. H. O uso das Geotecnologias para Análise de Expansão Urbana de Santa Gertrudes/SP. Trabalho de Conclusão de Curso (Bacharelado em Geografia), Rio Claro: IGCE/UNESP, 2016.

ASPACER (Associação Paulista das Cerâmicas de Revestimento). Disponível em: http://www.aspecer.com.br. Acessado em: junho de 2012.

BAENINGER, R. Crescimento das Cidades: metrópole e Interior do Brasil. In: . (Org.). População e Cidades subsídios para o planejamento e para as políticas sociais. Campinas: Núcleo de Estudos de PopulaçãoNEPO/Unicamp; Brasília: UNFPA, 2010, p. 209-222.

LANDIM, P. M. B. O Grupo Passa Dois na Bacia do Rio Corumbataí (SP). Boletim Divisão Geologia e Mineralogia/DNPM, $n^{\circ} .252,1967$.

RICHARDS, J. O. H. N. A. Remote sensing digital image analysis. 2. ed. Springer - Verlag, Berlim, 1993.

SANTOS, M. A Urbanização Brasileira, 5. ed., 2. Reinpr. Edusp, São Paulo, 2009. 